Cahiers $d u$ MONDE RUSSE

\section{Cahiers du monde russe}

Russie - Empire russe - Union soviétique et États indépendants

$48 / 4 \mid 2007$

Varia

\title{
Aleksandr Verhovskij, éd., Demokratija vertikali
}

\section{Françoise Daucé}

\section{OpenEdition \\ Journals}

Édition électronique

URL : https://journals.openedition.org/monderusse/6104

DOI : $10.4000 /$ monderusse. 6104

ISSN : $1777-5388$

Éditeur

Éditions de l'EHESS

Édition imprimée

Date de publication : 2 décembre 2007

Pagination : 778-781

ISBN : 978-2-7132-2148-4

ISSN : $1252-6576$

\section{Référence électronique}

Françoise Daucé, «Aleksandr Verhovskij, éd., Demokratija vertikali », Cahiers du monde russe [En ligne], 48/4 | 2007, mis en ligne le 16 juin 2009, consulté le 03 septembre 2022. URL : http:// journals.openedition.org/monderusse/6104; DOI : https://doi.org/10.4000/monderusse.6104

Ce document a été généré automatiquement le 3 septembre 2022.

Tous droits réservés 


\title{
Aleksandr Verhovskij, éd., Demokratija vertikali
}

\author{
Françoise Daucé
}

\section{RÉFÉRENCE}

Aleksandr VERHOVSKIJ, éd., Demokratija vertikali [La démocratie à la verticale]. Moscou : Sova, 2006, $347 \mathrm{p}$.

1 Cet ouvrage, dirigé par Aleksandr Verhovskij de l'ONG Sova, regroupe les contributions de plusieurs responsables associatifs russes autour de la question de l'évolution du régime politique en Russie. Le titre du recueil est un détournement du slogan de Vladimir Putin qui, au début de son premier mandat, avait promis de rétablir la "verticale du pouvoir ", c'est-à-dire de renforcer l'autorité du centre fédéral sur les régions. Aux yeux des auteurs, c'est finalement à la nature même du régime politique en Russie qu'il a porté atteinte, transformant les espoirs d'évolution vers une démocratie libérale en une démocratie « verticale », parfois dite aussi « souveraine » ou « dirigée » en clair, en un régime autoritaire. Le livre souhaite donc présenter les changements institutionnels qui ont progressivement été mis en place et qui ont modifié radicalement la nature du régime politique russe, que ce soit dans le domaine des médias, des élections, des libertés civiles ou de la politique étrangère. Il rassemble des textes et des auteurs très divers. Si la plupart des contributeurs sont des militants actifs de la société civile russe, d'autres sont des chercheurs, russes ou occidentaux. Certains textes, déjà parus dans des revues, sont republiés dans cet ouvrage, d'autres sont des articles originaux, les derniers enfin s'apparentent à des rapports associatifs. Le recueil s'achève par la transcription intégrale d'un séminaire sur la transition démocratique, organisé en octobre 2005 à Moscou et qui a regroupé les figures les plus importantes de la communauté des droits de l'homme. Si le lecteur peut être gêné par le caractère disparate et composite des textes réunis dans Demokratija vertikali, l'ensemble permet 
pourtant de dresser un tableau approfondi et convaincant des évolutions politiques et idéologiques en Russie aujourd'hui.

"Retour vers avant-hier», telle est la crainte de Tat'jana Lokšina, militante de l'association Demos, qui, d'entrée de jeu, rappelle les pressions croissantes qui s'exercent sur les associations indépendantes en Russie. Jusqu'en 2003, elle se souvient d'une vie de militante à Moscou, bien remplie mais sans peur, face à un État peu sympathique mais qui n'est plus «anthropophage». L'arrestation de Mihail Hodorkovskij marque un tournant, suivi d'un renforcement du contrôle des FSBšniki sur les associations, des événements tragiques de Beslan, des révolutions de couleur dans la CEI, l'ensemble alimentant la paranoïa du Kremlin. Les pressions du pouvoir sur les ONG lui rappellent de plus en plus le passé soviétique. Ces propos semblent confirmés par Sergej Lukaševskij, directeur de ce même Centre Demos, qui présente un article de synthèse sur les évolutions du régime russe depuis 2000. Il y souligne les atteintes successives à l'exercice du suffrage universel (au niveau fédéral comme dans les régions), à la séparation des pouvoirs, à la liberté d'expression, à la liberté d'association, à la liberté d'entreprendre. Il évoque, en conclusion, un processus de « dé-libéralisation » qui touche toutes les sphères du pouvoir.

3 À ces contributions générales succèdent des rapports précis et exhaustifs sur l'évolution législative et politique dans le pays. Lev Levinson propose un article intitulé « Nous n'avons pas le choix », qui peut aussi se lire " Nous n'avons pas d'élections ». L'auteur revient de manière précise et systématique sur tous les changements dans le domaine législatif concernant les partis politiques et l'organisation des élections depuis 2000. Soit des retouches législatives nombreuses, qui, au final, modifient radicalement le paysage partisan et électoral russe. Comme le souligne Levinson, au terme des amendements adoptés, plus aucun parti d'opposition n'est en mesure d'émerger pour concurrencer sérieusement le parti du pouvoir. Il regrette finalement le système politique, même imparfait, qui avait été mis en place au milieu des années 1990. Svetlana Kovaleva, quant à elle, fait un bilan du travail de veille réalisé par le centre Demos sur les atteintes au droit de manifester. Elle revient sur les manifestations contre la monétisation des avantages sociaux en janvier 2005, que le pouvoir a tenté de discréditer en y voyant la main de forces politiques intéressées à la déstabilisation de l'État (sans pouvoir incriminer cependant de "forces étrangères » cette fois). Depuis, l'administration a élaboré des dispositions formelles et informelles pour limiter les manifestations dans le pays. Les forces de l'ordre n'hésitent pas à intervenir avant ou pendant les manifestations pour arrêter les participants les plus actifs. Vladimir Pribylovskij, enfin, propose une chronique des atteintes portées contre la presse d'opposition entre 2002 et 2006. La couverture de la prise d'otage au théâtre Nord-Ost apparaît comme un tournant dans l'histoire des pressions du pouvoir sur les journalistes. À l'issue de cet événement, plusieurs journaux sont repris en main. La liste des atteintes à la liberté de la presse entre 2002 et 2006 est impressionnante. Chaque événement pris séparément peut sembler conjoncturel ou fortuit, mais l'ensemble figure un plan rationnel et tenace de contrôle des médias. Sous couvert de conflits juridico-économiques, le gouvernement réussit aussi à renouveler radicalement la rédaction des journaux et des chaînes d'opposition.

4 À ces textes succèdent des contributions plus théoriques sur l'évolution idéologique et culturelle du pouvoir politique russe. Aleksandr Verhovskij s'intéresse à l'utilisation de la religion par le pouvoir politique. Il souligne que le patriarcat a réussi à imposer dans le discours politique le concept de "sécurité spirituelle ", mais qu'il peine cependant à 
rallier l'administration à son idée de "civilisation orthodoxe». Le pouvoir, et notamment Putin, garde finalement à distance une Église qui tente de s'imposer en partenaire privilégié de l'État. Marlène Laruelle, pour sa part, étudie les représentations de l'identité russe en lien avec la question des migrations vers la Russie. Si les années 1990 ont vu le retour de nombreux Russes de l'étranger proche en Russie, ce flot s'est progressivement tari, ce qui pose aujourd'hui la question de l'arrivée de populations migrantes non Russes dans le pays. Depuis la fin des années 1990, le pouvoir s'intéresse à la mise en place de facilités pour le retour des Russes au pays, développant une vision ethnique des migrations tout en prenant en compte dans la pratique ses dimensions économiques et sociales. Enfin, Tatiana Lokšina étudie les relations entre la Russie et l'Union européenne à travers l'exemple des discussions bilatérales à propos de la Tchétchénie. Se fondant sur des exemples concrets de rencontres organisées à Bruxelles, elle montre les incompréhensions qui séparent défenseurs des droits de l'homme russes, fonctionnaires européens et différents représentants de la cause tchétchène, sans parler des représentants du pouvoir russe. Son témoignage traduit une déception à l'égard des responsables européens qui semblent masquer leur impuissance derrière une politesse et une affabilité stériles.

Le dernier quart du livre est consacré à la retranscription intégrale du séminaire sur « Les perspectives de la transition démocratique", organisé en octobre 2005 à Moscou par plusieurs associations non gouvernementales (Sova, Demos et Panorama). Les interventions concernent, d'une part, les aspects conceptuels de la transition démocratique dans la Russie actuelle et, de l'autre, la question de l'activité des ONG et des organisations politiques dans ce processus. Cette dernière partie est extrêmement intéressante. Les intervenants s'interrogent sur les évolutions politiques intervenues en Russie depuis l'arrivée de Putin au pouvoir et sur les perspectives qui se profilent. Les réflexions sur la nature du régime politique russe et sur les relations entre le pouvoir et la société sont stimulantes.

6 Cet ouvrage propose une critique raisonnée et rigoureuse du régime politique russe actuel. Menée par des militants de la société civile, cette critique reste cependant fortement influencée par les modèles démocratiques et libéraux occidentaux. Le titre du séminaire final en témoigne. L'idéal politique des militants associatifs est fortement influencé par la science politique occidentale et fondé sur «des règles normales de fonctionnement de la démocratie » qui lui sont empruntées. Les réflexions critiques sur la validité théorique de ce modèle sont peu nombreuses, tout comme les contributions qui discutent la pertinence du modèle libéral. Si tous les participants constatent que la démocratie libérale a été remise en cause en Russie, rares sont ceux qui s'interrogent sur la façon dont les expérimentations libérales ont été conduites dans le pays. 